\title{
А.А. Широв
}

Институт народнохозяйственного прогнозирования РАН, Москва

\section{Пандемический кризис экономики: механизмы развития и решения в области экономической политики}

Аннотация. Пандемия новой коронавирусной инфекции поставила новые задачи перед специалистами в области экономического анализа и экономической политики. Отличие пандемического кризиса от механизмов традиционного экономического кризиса в рамках бизнесцикла требует описания ключевых механизмов его развития. Сравнительно более благоприятные макроэкономические результаты развития российской экономики в 2020 г. определялись ее структурными особенностями и параметрами экономической политики. В то же время кризис привел к существенным социальным потерям, которые выразились в росте избыточной смертности и снижении реальных доходов населения, безработице. Кризис показал невозможность адресной поддержки всех пострадавших слоев населения. В связи с этим быстрое восстановление экономической активности на основе государственной поддержки может стать наиболее эффективным способом восстановления уровня и качества жизни населения.

Ключевые слова: коронакризис, экономический рост, доходы населения, антикризисная политика, восстановление экономики.

Классификация JEL: E44, E61, O11.

DOI: $10.31737 / 2221-2264-2021-49-1-10$

\section{Особенности экономического кризиса на фоне пандемии}

Пандемия нового коронавируса COVID-19 привела к существенным социальноэкономическим потерям практически во всех крупных экономиках мира. По оценкам Международного валютного фонда, общий спад мирового ВВП по итогам 2020 г. составил 3,5\%. Таким образом, человечество столкнулось с одним из самых серьезных экономических кризисов за весь период оценок глобальной экономической динамики (Loayza et al., 2020). В российской экономике спад оказался немного ниже $-3,1 \%$.

Уникальность кризиса, связанного с распространением новой коронавирусной инфекции, заставляет правительства и әкспертное сообщество рассматривать различные особенности его влияния на экономическую динамику и политику (Baker McKenzie, 2020).

Неоднократно отмечалось, что особенность формирования текущего кризиса для экономики нашей страны обусловлена действием двух связанных, но специфических факторов: 1) развитие эпидемиологической ситуации в стране; 2) снижение добычи и экспорта углеводородов в рамках сделки ОПЭК+ (Клепач, 2020).
Уникальность пандемического кризиса определяется тем, что он не имеет непосредственного отношения к текущей экономической конъюнктуре. Негативно влияют на экономику прежде всего ограничительные меры, предпринимаемые властями в целях защиты населения от распространения инфекции (Колодко, 2020). Другой важный фактор интенсивность государственной противоциклической политики.

Мировая экономика уже пережила, как минимум, две волны нарастания заболеваемости COVID-19. Первая имела наиболее интенсивный характер во II квартале 2020 г., а вторая - в конце 2020 - начале 2021 г. К концу февраля 2021 г. число заболевших новой коронавирусной инфекцией в мире превысило 62 млн, а в России - 4 млн человек.

Масштабы инфекции были столь огромными, что результаты, которые продемонстрировала российская экономика в 2020 г., могут быть признаны позитивными. Одним из критериев этого является соотношение использованного правительством антикризисного пакета и итогового экономического результата. По нашим оценкам, российское правительство потратило на борьбу с кризисом примерно $4 \%$ 
ВВП. В то же время крупнейшие экономики мира выделили на антикризисную политику существенно большие суммы. Например, антикризисный пакет в Китае оценивается в $13 \%$ ВВП, в США - 25\%, в Германии и Японии примерно 60\% (Makin, Layton, 2021)!

\section{Российская экономика в условиях коронакризиса}

Несмотря на относительно небольшой объем стимулирующих мер, российскому правительству удалось обеспечить набор противоциклических мероприятий, который позволил демпфировать основные негативные последствия кризиса в сфере экономики.

Можно отметить, что единственным элементом счета потребления ВВП, продемонстрировавшим положительную динамику, стало государственное потребление, рост которого в 2020 г. составил 4\%. По нашим оценкам, позитивный вклад государственного потребления в формирование ВВП составил не менее 0,7 п.п. (см. таблицу). Это наиболее наглядный пример значимых мер противоциклической политики государства в период кризиса. Стоит отметить, что столь существенный положительный вклад этой экономической меры в динамику ВВП в период кризисов в нашей стране фиксируется впервые. Даже в период кризиса 2008-2009 гг., когда правительство сформировало многоуровневый антикризисный пакет, положительный вклад государственного потребления в экономическую динамику не превысил 0,3 п.п. Неудивительно, что расходы Федерального бюджета в номинальном выражении в 2020 г. выросли, по сравнению с предыдущим годом, сразу на 26,6\% (рис. 1).

Еще один вывод из анализа счета использования ВВП состоит в том, что текущая структура российского экспорта представляет собой не «проклятье», а важнейший элемент стабилизации экономики в самых сложных условиях. Достаточно сказать, что российский экспорт на фоне глобального экономического хаоса во II квартале 2020 г. продемонстрировал положительную динамику.

В целом в мировой экономике повторилась ситуация, когда спрос на сырьевую продукцию всех видов сокращается медленнее, чем на конечную (Vidya, Prabheesh, 2020). В итоге при прочих равных условиях спад в странах, чья экономика зависит от экспорта конечной продукции, почти всегда имеет бо́льшие масштабы, чем в странах с преобладанием сырьевого экспорта. Происходит это не только потому, что сырье непосредственно связано с условнопостоянными расходами, но и потому, что в экспортирующих сырье странах происходит

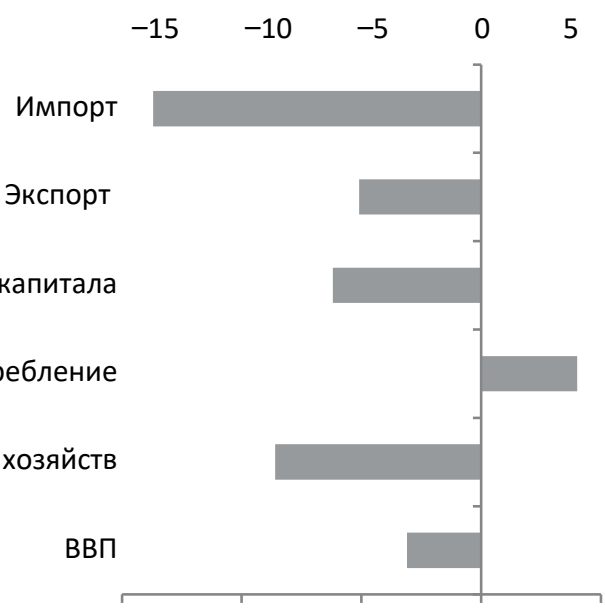

Pис. 1

Динамика основных элементов счета использования ВВП, прирост в \%

Источник: Росстат. 
Таблица 1

Вклады элементов конечного спроса в экономическую динамику в периоды кризисов

\begin{tabular}{|l|c|c|c|}
\hline \multicolumn{1}{|c|}{ Элемент конечного спроса } & 2009 г. & 2015 г. & 2015 г. \\
\hline \hline $\begin{array}{l}\text { Валовой внутренний продукт, рост в \% к предыду- } \\
\text { щему году } \\
\text { В том числе, п.п. }\end{array}$ & $-7,9$ & $-2,0$ & $-3,1$ \\
\hline Потребление домашних хозяйств & $-5,0$ & $-5,7$ & $-4,8$ \\
\hline Государственное потребление & 0,3 & $-0,7$ & 0,7 \\
\hline Валовое накопление основного капитала & $-4,7$ & $-2,6$ & $-1,4$ \\
\hline Прирост запасов & $-5,4$ & $-0,5$ & 0,4 \\
\hline Экспорт & $-1,7$ & 0,9 & $-1,4$ \\
\hline Импорт & 11,3 & 7,1 & 3,4 \\
\hline Статистическое расхождение & $-2,8$ & $-0,5$ & 0,0 \\
\hline
\end{tabular}

Источник: Росстат, расчеты автора.

активное балансирование платежного баланса путем изменения курса, что способствует росту чистого экспорта.

Так произошло в России и в этот раз. В результате опережающего спада импорта положительный вклад чистого экспорта в экономическую динамику составил 3,4 п.п., что почти на $70 \%$ компенсировало негативный вклад в ВВП такого фактора экономического роста, как потребление домашних хозяйств $(-4,8$ п.п.).

Если рассмотреть экономическую динамику со стороны счета производства ВВП, необходимо отметить два вида деятельности, демонстрировавших положительную динамику во время кризиса (рис. 2). Во-первых, - сектор государственного управления, добавленная стоимость в котором росла под воздействием симулирующих программ правительства. Во-вторых, - сектор финансовой и страховой деятельности, реальная добавленная стоимость которого в 2020 г. выросла почти на $8 \%$. Вообще, увеличение доходов в финансовом секторе стало особенностью российской экономики в периоды кризисов, которая не поддерживает ее устойчивости в период шоков.

Заметна позитивная динамика в строительном секторе, который был поддержан путем продолжения реализации национальных проектов и программы льготной ипотеки, а также отсутствие значимой негативной динамики в сельском хозяйстве и обрабатывающих производствах.
Промышленное производство в период кризиса характеризовалось разнонаправленной динамикой. В большинстве видов деятельности по итогам второго квартала наблюдался глубокий спад. Исключением стало пищевое производство (в том числе за счет частичного перетока спроса из сектора общественного питания), фармацевтическое и химическое производства, а также производство медицинских изделий. После отмены режима самоизоляции почти во всех видах деятельности наблюдался значимый подъем, характеризовавшийся достаточно высокими темпами роста производства. Такая динамика является характерной особенностью пандемического кризиса, при которой в результате карантинных мероприятий формируется значительный отложенный спрос у потребителей, производителей и в торговой сети.

Анализ динамики производства и торговли в III квартале 2020 г. дает основания полагать, что бизнес и государство были не готовы к такому изменению конъюнктуры. Скорее они готовились к плавному восстановлению спроса наподобие того, как это происходит в результате восстановления экономики при выходе из кризиса в рамках бизнес-цикла. Однако длительный период жесткого карантина сформировал достаточно мощный нереализованный спрос. В результате как в России, так и в крупнейших экономиках мира формировались локальные дефициты продукции, которые сдерживали восстановительный рост. 


\begin{tabular}{|c|c|c|c|c|c|}
\hline \multicolumn{6}{|l|}{ Деятельность домашних хозяйств как работодателей } \\
\hline \multicolumn{6}{|l|}{ Предоставление прочих видов услуг } \\
\hline \multicolumn{6}{|l|}{ Деятельность в области культуры, спорта, организации досуга и развлечений } \\
\hline \multicolumn{6}{|l|}{ Деятельность в области здравоохранения } \\
\hline \multicolumn{6}{|c|}{ Образование } \\
\hline \multicolumn{6}{|l|}{ Государственное управление } \\
\hline \multicolumn{6}{|l|}{ Деятельность административная } \\
\hline \multicolumn{6}{|l|}{ Деятельность профессиональная, научная и техническая } \\
\hline \multicolumn{6}{|l|}{ Деятельность по операциям с недвижимым имуществом } \\
\hline \multicolumn{6}{|l|}{ Деятельность финансовая и страховая } \\
\hline \multicolumn{6}{|l|}{ Деятельность в области информации и связи } \\
\hline \multicolumn{6}{|l|}{ Деятельность гостиниц и ресторанов } \\
\hline \multicolumn{6}{|l|}{ Транспортировка и хранение } \\
\hline \multicolumn{6}{|l|}{ Торговля оптовая и розничная } \\
\hline \multicolumn{6}{|l|}{ Строительство } \\
\hline \multicolumn{6}{|l|}{ Водоснабжение; водоотведение } \\
\hline \multicolumn{6}{|l|}{ Обеспечение электрической энергией, газом и паром } \\
\hline \multicolumn{6}{|l|}{ Обрабатывающие производства } \\
\hline \multicolumn{6}{|l|}{ Добыча полезных ископаемых } \\
\hline \multicolumn{6}{|l|}{ Сельское, лесное хозяйство, охота, рыболовство и рыбоводство } \\
\hline \multicolumn{6}{|l|}{ ВВП } \\
\hline-30 & $-25-20$ & -15 & -10 & -5 & 10 \\
\hline
\end{tabular}

Puc. 2

Динамика элементов счета производства ВВП, прирост в \% к предыдушему году

Источник: Росстат.

Восстановление спроса после окончания волны отложенного спроса оказалось сопоставимо с классической траекторией восстановления в рамках бизнес-цикла и определялось новым уровнем равновесия спроса и предложения.

Анализ динамики ВВП и промышленного производства в 2020 г. позволяет сделать ряд обобщающих выводов об особенностях поведения российской экономики в период пандемического кризиса:

- решения, связанные с введением карантинных мер, были селективными, что позволило обеспечить приемлемую динамику в сельскохозяйственном производстве, оборонно-промышленном комплексе, ряде сырьевых производств, строительстве;

- относительно низкая доля непроизводственных услуг при формировании ВВП (примерно на 10 п.п. ниже, чем в странах EG) снижала потенциал экономического спада;
- преобладание сырьевых товаров в структуре әкспорта и конечных продуктов в структуре импорта способствовало позитивному влиянию чистого экспорта на экономическую динамику;

- низкие базовые характеристики экономического роста в период, предшествовавший кризису, также стали естественной причиной, ограничившей спад экономики;

- антикризисные действия правительства добавили к экономической динамике до 1,5 п.п. как по каналам государственного потребления, так и по каналам потребительского и инвестиционного спроса.

По итогам 2020 г. можно констатировать позитивные результаты борьбы с экономическими последствиями кризиса. При этом были сохранены резервы и обеспечена макрофинансовая стабильность. Безусловно, этому способствовал факт, что государству, в отличие от кризиса 2009 г., почти не пришлось тратить финансовые ресурсы на поддержание 
банковской системы (Алексашенко, Миронов, Мирошниченко, 2011). По нашим оценкам, с учетом свободной ликвидности в условиях 2020 г. российские банки могли бы действовать в режиме самоизоляции примерно в течение трех месяцев без существенного ухудшения их финансовой устойчивости. Именно этим периодом, по-видимому, и ограничиваются экономические возможности проведения жестких карантинных мероприятий при текущем состоянии российской экономики.

\section{Социальный шок в условиях пандемического кризиса}

Относительно благоприятные макроэкономические показатели, достигнутые в 2020 г., сопровождались значительными потерями социального характера.

Прежде всего речь идет о значительном росте избыточной смертности, который по итогам 2020 г. составил почти 18\%, или 323,8 тыс. человек. Всего в 2020 г. население России сократилось почти на полмиллиона человек. Это - один из самых высоких показателей в мире (Meyerowitz-Katz, Merone, 2020). Не говоря о том, что каждая смерть - это трагедия. Понесенные страной демографические потери непосредственно повлияли и на экономическую динамику. По нашим оценкам, негативный вклад избыточной смертности в ВВП составил не менее 0,2 п.п. Важно также, что снижение численности населения, произошедшее в 2020 г., будет продолжать негативно влиять, пусть и не очень значительно, на среднесрочный потенциал роста.

Второй крайне негативный момент состоит в том, что наибольший удар кризис нанес по доходам населения. За период 20142019 гг. реальные располагаемые доходы населения снизились на 6,3\%. По итогам 2020 г. реальные располагаемые доходы уменьшились еще на 3,5\%. Таким образом, спад относительно уровня 2013 г. составил более 10\%. Такие цифры падения доходов формируют вполне понятные требования к социальной политике в период посткризисного восстановления экономики (Аганбегян и др., 2020).

Опыт 2020 г. показал, что правитель- ство может действовать оперативно и эффективно в ходе реализации антикризисных мер социального характера. За счет таких мер были поддержаны доходы семей с несовершеннолетними детьми, работники наиболее пострадавших секторов экономики, пенсионеры. Как показывает анализ статистики розничного товарооборота, а также высокочастотных данных российских банков, большая часть дополнительных средств, полученных населением, пошла на покупку продовольствия, медикаментов, товаров для детей и ремонт жилья. В целом можно отметить, что дополнительная социальная поддержка интенсифицировала спрос населения на отечественную продукцию в период июля-сентября 2020 г., что существенно поддержало российскую экономику.

Парадокс кризиса 2020 г. состоит в том, что на фоне роста реальных заработных плат и пенсий был зафиксирован спад реальных денежных доходов населения в целом. Произошло это потому, что существенно снизились доходы предпринимателей, работающих в среднем и мелком бизнесе, а также у тех, кто был занят неофициально. Оказалось, что у государства отсутствуют действенные каналы адресной помощи этим группам граждан. Спад доходов ограничивает восстановление российской экономики, в которой спрос населения формирует около $50 \%$ ВВП.

Проблемы потребительского спроса связаны не только с динамикой доходов населения в 2020 г. Наиболее существенным фактором является структура доходов и расходов по отдельным группам населения. Почти у половины наименее обеспеченных российских семей доля продовольственных товаров в структуре расходов - в среднем свыше $40 \%$. Значительную долю составляют обязательные платежи (Широв, Потапенко, 2020). Средств для формирования сбережений у этой половины российских семей крайне мало. У высокодоходных групп населения ситуация обратная. В этой выборке отмечается высокая норма сбережения и также высокая доля импорта в потреблении. В условиях изменения доходов населения в 2020 г. в целом в доходах высокооплачиваемых групп населения наблюдалась 
позитивная динамика. У тех, кто попал под действие социальных программ (малообеспеченные семьи с детьми, официально занятые работники сферы непроизводственных услуг), также не было ощутимого спада доходов. Провал произошел у среднедоходных групп населения, прежде всего в среде мелких и средних предпринимателей, занятых в секторе непроизводственных услуг. Восстановление их доходов возможно только после перехода к активному посткризисному восстановлению экономики.

\section{Перспективы посткризисного восстановления экономики}

С учетом второй волны заболеваемости кризис охватил, как минимум, один годовой цикл: с I квартала 2020 г. по II квартал 2021 г. Важнейшим фактором неопределенности в мировой и российской экономике остается уровень заболеваемости коронавирусной инфекцией и әффективность действия противовирусных вакцин. Если предположить, что массовая вакцинация в первом полугодии состоится и будет эффективной, это даст важнейший импульс глобальному восстановлению спроса, что даст возможность обсуждать конструктивные сценарии восстановления роста. При этом ориентиром для восстановления экономики мог бы стать уровень доходов населения, достигнутый к 2013 г.

Неприемлемость инерционной траектории восстановления экономики диктуется прежде всего нарастанием социально-экономических проблем, которые были усилены в период коронакризиса. Среди всех действий, связанных с активизацией экономической деятельности, наиболее эффективными могут стать решения, направленные на рост потребительского спроса и запуск нового инвестиционного цикла.

Текущая ситуация в финансовой сфере характеризуется сохранением относительно мягкой денежно-кредитной политики и относительно жесткой бюджетной политики. Проблема состоит в том, что такая комбинация, вполне приемлемая для развитых стран, у нас может оказаться мало эффективной.
В условиях жестких ограничений спроса одни только монетарные методы не могут сформировать достаточного импульса для расширения масштабов кредитования и оживления инвестиционного спроса. Требуется дополнительная поддержка со стороны бюджетной системы.

Опыт 2020 г. показал, что такая поддержка может быть и существенной, и әффективной. Например, рост бюджетных расходов и значительное уменьшение экономического спада поддержал наименее обеспеченные группы населения и оказал әффективную помощь системообразующим секторам экономики.

Трансформации в бюджетной политике позволили сформировать новые возможности для финансирования государственных расходов. В 2020 г. почти весь дефицит бюджета был профинансирован за счет заимствований. При текущем уровне государственного долга такой вариант финансирования не является рисковым, а кроме того, дает возможность банкам эффективно использовать свободную ликвидность и позволяет развивать внутренний финансовый рынок. Средства ФНБ могут быть потрачены на решение задач долгосрочного инвестиционного характера. В такой конструкции Фонд национального благосостояния (ФНБ) может постепенно трансформироваться в бюджет развития, средства из которого направляются на реализацию инвестиционных проектов, расширяющих среднесрочный потенциал экономического роста.

Для активизации инвестиционной активности бизнеса нужен рост спроса, в том числе потребительского. А для этого необходим рост реальных доходов населения. Конечно, можно ожидать, что он постепенно восстановится в результате балансирования рыночных факторов. Но это долгий путь. Он предполагает постепенное расширение экономической активности на фоне улучшения ситуации во внешнем мире, наращивание сначала государственных, а затем и частных инвестиций. И только вслед за этим начнется рост доходов и заработных плат. Такое восстановление спроса может занять до трех-четырех лет. 
С учетом уже понесенных социальных потерь такие сроки нельзя признать приемлемыми.

Требуется дать боле мощный импульс процессу восстановления уровня потребительского спроса. Начать можно было бы с работников бюджетной сферы. Реформа оплаты труда, активно проводившаяся в 20122018 гг., привела к росту средних заработных плат в науке, здравоохранении и образовании. Однако после 2018 г. дальнейшего опережающего роста оплаты труда в бюджетном секторе не происходило.

В результате средняя заработная плата в образовании на 2020 г. оценивается лишь в 78\% от средней по стране, а в здравоохранении - в 104,2\%. При этом в здравоохранении превышение среднего уровня заработной платы произошло в 2020 г. (средний рост номинальной средней заработной платы медицинских работников составил более 20\%) и было связано с временными выплатами врачам и медицинскому персоналу, непосредственно участвовавшим в борьбе с пандемией.

Несмотря на рост реальных пенсий в 2020 г., соотношение средних пенсий и заработных плат по результатам года составило уже менее $30 \%$, что можно назвать критическим уровнем, особенно с учетом прошедшего повышения пенсионного возраста. Соответственно, и здесь накопились социальные долги.

Возникает вопрос, а не приведут ли действия, связанные с повышением уровня оплаты труда работников бюджетной сферы, а также пенсий, к ухудшению параметров макроэкономической стабильности. Наши оценки показывают, что нет. Во-первых, потребительский спрос сейчас настолько слаб, что его некоторое оживление вряд ли спровоцирует существенный рост цен. Более вероятно, что начнется постепенная загрузка конкурентоспособных мощностей, ориентированных на удовлетворение потребностей населения. Во-вторых, как показывает опыт противоциклической политики 2020 г., практически вся динамика роста цен объяснялась изменением курса рубля и цен на мировых товарных рынках. В то время как меры поддержки экономики позитивно влияли на общую макроэконо- мическую ситуацию. В-третьих, рост доходов в бюджетном секторе поддержит не только экономику в целом. Он прежде всего повысит спрос на критически важных для восстановления роста рынках: жилищном, автомобильном, бытовой техники и т.д.

Можно предположить, что расширение уровня государственной инвестиционной активности может последовать после прояснения ключевых экономических трендов 2021 г., т.е. на границе первого и второго кварталов. При этом наиболее важные направления поддержки экономики могли бы быть связаны с финансированием национальных проектов в версии 2,0 в части развития инфраструктуры, реализации социальных программ и т.д. Активность государства в той или иной степени будет подхвачена бизнесом, а это может стать основой для нового подъема отечественной экономики в целом.

В целом набор действий, связанных с поддержанием доходов населения и запуском инвестиционного цикла, вполне могут обеспечить российской экономике в ближайшие три года среднегодовой рост на уровне $3,0-3,5 \%$.

\section{ЛИТЕРАТУРА / REFERENCES}

Аганбегян А.Г., Клепач А.Н., Порфирьев Б.Н., Узяков М.Н., Широв А.А. (2020). Постпандемическое восстановление российской экономики и переход к устойчивому социально-экономическому развитию // Проблемь прогнозирования. №. 6. С. 18-26. [Aganbegyan A.G., Klepach A.N., Porfiryev B.N., Uzyakov M.N., Shirov A.A. (2020). Postpandemic recovery: The Russian economy and the transition to sustainable Social and economic development. Studies on Russian Economic Development, 31 (6), 599-605 (in Russian).]

Алексашенко С., Миронов В., Мирошниченко Д. (2011). Российский кризис и антикризисный пакет: цели, масштабы, эффективность // Вопросы экономики. Т. 2. С. 23-49 [Alexashenko S., Mironov V., Miroshnichenko D. (2011). 
Crisis and anti-crisis package in Russia: Targets, scale, efficiency. Voprosy Ekonomiki, 2, 23-49 (in Russian).]

Клепач А.Н. (2020). Российская экономика: шок от коронавируса и перспективы восстановления // Научнъе трудъ Вольного экономического общества России. Т. 222. №.

2. C. 72-87. [Klepach A.N. (2020). The Russian economy: The shock of the coronavirus and the prospects for recovery. The Scientific works of the free economic society of Russia. B. 222, 2, 72-87 (in Russian).]

Колодко Г.В. (2020). Последствия. Экономика и политика в постпандемическом мире // Вопросъ экономики. Т. 5. C. 25-44. [Kolodko G.V. (2020). After. Economics and politics of the postpandemic world. Voprosy Ekonomiki, 5, 2544 (in Russian).]

Широв А.А., Потапенко В.В. (2020). Парадокс российского потребления / / ЭКО. №. 6. C. 8-25. [Shirov A.A., Potapenko V.V. (2020). The paradox of Russian consumption. ECO, 6, 8-25 (in Russian).]
Baker McKenzie (2020). Supply chains reimagined: Recovery and renewal in Asia Pacific and Beyond. Available at: https://www.bakermckenzie.com/-/media/files/insight/ publications / 2020/08/supply-chainsreimagined_17-aug.pdf?la=en

Loayza N.V., Sanghi A., Shaharuddin N., Wuester L. (2020). Recovery from the pandemic crisis: Balancing short-term and long-term concerns. Research and Policy Brief. Washington: World Bank.

Makin A.J., Layton A. (2021). The global fiscal response to COVID-19: Risks and repercussions. Economic Analysis and Policy, 69, 340-349.

Meyerowitz-Katz G., Merone L. (2020). A systematic review and meta-analysis of published research data on COVID-19 infection-fatality rates. International Journal of Infectious Diseases. doi: 10.1101/2020.05.03.20089854

Vidya C.T., Prabheesh K.P. (2020). Implications of COVID-19 pandemic on the global trade networks. Emerging Markets Finance and Trade, 56, 10, 2408-2421.

Поступила в редакиию 23.02.2021

Received 23.02.2021

\section{A.A. Shirov}

Institute of Economic Forecasting RAS, Moscow, Russia

\section{The pandemic crisis: The mechanisms of development and solutions for economic policy}

Abstract. The new coronavirus pandemic has created new challenges for experts in economic analysis and substantiation of economic policy. The difference between a pandemic crisis and the mechanisms of a traditional business cycle crisis requires a description of the key mechanisms of its development. The relatively more favorable macroeconomic results of the Russian economy in 2020 were determined both by its structural features and by the parameters of economic policy. At the same time, the crisis led to significant social losses, which resulted in an increase in excess mortality and a decrease in real incomes of the population, and unemployment rising. The crisis has shown the impossibility of targeted support for all the affected segments of the population. In this regard, a rapid recovery of economic activity on the basis of state support can be the most effective way to restore the level and quality of life of the population.

Keywords: coronacrisis, economic growth, income of the population, anti-crisis policy, economic recovery.

JEL Classification: E44, E61, O11.

DOI: $10.31737 / 2221-2264-2021-49-1-10$ 